\title{
Diagnosis and treatment of disseminated intravascular coagulation (DIC) according to four DIC guidelines
}

\author{
Hideo Wada ${ }^{1 *}$, Takeshi Matsumoto ${ }^{2}$ and Yoshiki Yamashita ${ }^{3}$
}

\begin{abstract}
Disseminated intravascular coagulation (DIC) is categorized into bleeding, organ failure, massive bleeding, and non-symptomatic types according to the sum of vectors for hypercoagulation and hyperfibrinolysis. The British Committee for Standards in Haematology, Japanese Society of Thrombosis and Hemostasis, and the Italian Society for Thrombosis and Haemostasis published separate guidelines for DIC; however, there are several differences between these three sets of guidelines. Therefore, the International Society of Thrombosis and Haemostasis (ISTH) recently harmonized these differences and published the guidance of diagnosis and treatment for DIC. There are three different diagnostic criteria according to the Japanese Ministry Health, Labour and Welfare, ISTH, and Japanese Association of Acute Medicine. The first and second criteria can be used to diagnose the bleeding or massive bleeding types of DIC, while the third criteria cover organ failure and the massive bleeding type of DIC. Treatment of underlying conditions is recommended in three types of DIC, with the exception of massive bleeding. Blood transfusions are recommended in patients with the bleeding and massive bleeding types of DIC. Meanwhile, treatment with heparin is recommended in those with the non-symptomatic type of DIC. The administration of synthetic protease inhibitors and antifibrinolytic therapy is recommended in patients with the bleeding and massive bleeding types of DIC. Furthermore, the administration of natural protease inhibitors is recommended in patients with the organ failure type of DIC, while antifibrinolytic treatment is not. The diagnosis and treatment of DIC should be carried out in accordance with the type of DIC.
\end{abstract}

Keywords: Disseminated intravascular coagulation (DIC), Bleeding type, Organ failure type, Massive bleeding type, Non-symptomatic type, Guidelines

\section{Introduction}

Disseminated intravascular coagulation (DIC) is a syndrome characterized by the systemic activation of blood coagulation, which generates intravascular thrombin and fibrin, resulting in the thrombosis of small- to mediumsized vessels and ultimately organ dysfunction and severe bleeding [1,2]. DIC may result as a complication of infection, solid cancers, hematological malignancies, obstetric diseases, trauma, aneurysms, and liver diseases, etc., each of which presents characteristic features related to the underlying disorder. The diagnosis and treatment of DIC must therefore consider these underlying etiological

\footnotetext{
*Correspondence: wadahide@clin.medic.mie-u.ac.jp

'Department of Molecular and Laboratory Medicine, Mie University School of Medicine, 2-174 Edobashi, Tsu, Mie 514-8507, Japan

Full list of author information is available at the end of the article
}

features. The type of DIC is related to the underlying disorder. Three guidelines for diagnosis and treatment of DIC [3-5] have been published in the literature by the British Committee for Standards in Haematology (BCSH), Japanese Society of Thrombosis and Hemostasis (JSTH), and Italian Society for Thrombosis and Haemostasis (SISET). Although these three guidelines are broadly similar, there are variations in several recommendations regarding DIC treatment. Therefore, the subcommittee for DIC of the Scientific and Standardization Committee (SSC)/International Society of Thrombosis and Haemostasis (ISTH) harmonized these three guidelines in a report entitled, Guidance for the diagnosis and treatment of DIC from harmonization of the recommendations from three guidelines [6] (Table 1). The present review describes 
Table 1 Differences in recommendations among three guidelines from BCSH, JSTH, and SISET and harmonized ISTH/SSC guidance

\begin{tabular}{|c|c|c|c|c|}
\hline & BCSH & JSTH & SISET & ISTH/SSC \\
\hline Scoring system for DIC & $\mathrm{R}$; grade $\mathrm{C}$ & $\mathrm{R}^{\mathrm{a}}$ & R; grade C & R; high quality \\
\hline Single test analysis for DIC & NR & $N R^{a}$ & NR; grade D & R high quality \\
\hline Treatment of underlying disease & $\mathrm{R}$; grade $\mathrm{C}$ & $\mathrm{R}$; consensus & R; cornerstone & $\mathrm{R}$; moderate quality \\
\hline Platelet concentration & $\mathrm{R}$; grade $\mathrm{C}$ & $\mathrm{R}$; consensus & $\mathrm{R}$; grade $\mathrm{D}$ & R; low quality \\
\hline FFP & $\mathrm{R}$; grade C & $\mathrm{R}$; consensus & $\mathrm{R}$; grade D & R; low quality \\
\hline Fibrinogen, cryoprecipitate & $\mathrm{R}$; grade $\mathrm{C}$ & Disregard & $\mathrm{R}$; grade $\mathrm{D}$ & R; low quality \\
\hline FVlla & Disregard & Disregard & NR; grade D & NM \\
\hline UFH (treatment) & $\mathrm{R}$; grade $\mathrm{C}$ & R; level C & NR; grade D & R; low quality \\
\hline UFH (prophylaxis for VTE) & $\mathrm{R}$; grade A & Disregard & $\mathrm{R}$ & R; high quality \\
\hline LMWH & Disregard & R; level B2 & $\mathrm{R}$; grade $\mathrm{D}$ & Preferred to UFH \\
\hline Heparin sulfate & Disregard & R; level C & & NM \\
\hline Synthetic protease & Disregard & R; level B2 & NR; grade D & NM \\
\hline rhAPC & $\mathrm{R}$; grade A & Disregard & $\mathrm{R}$; grade D & Need for further Ed from RCT \\
\hline AT & NR; grade A & $\mathrm{R} ; \mathrm{B} 1$ & NR; grade D & Need for further Ed from RCT \\
\hline rhTM & Disregard & Disregard & NR; grade B & Need for further Ed from RCT \\
\hline Antifibrinolytic agents & $\mathrm{R}$; grade C & NR; level D & & R; low quality \\
\hline Plasma exchange & Disregard & Disregard & NR; grade D & NM \\
\hline
\end{tabular}

$\mathrm{R}$, recommendation; NR, not recommendation; $\mathrm{R}^{\mathrm{a}}$, suggestive recommendation; NM, not mention; Ed, evidence; FFP, fresh frozen plasma; PCC, FVIla, activated coagulation factor VII; UFH, unfractionated heparin; LMWH, low molecular weight heparin; rh, recombinant human; APC, activated protein C; AT, antithrombin; TM, thrombomodulin; RCT, randomized control trial.

several recommendations for the diagnosis and treatment of DIC related to the type of DIC.

\section{Review}

\section{Pathophysiology of DIC}

Abnormalities of the hemostatic system in patients with DIC result from the sum of vectors for hypercoagulation and hyperfibrinolysis (Figure 1). When the vector for hyperfibrinolysis is remarkable and dominant, bleeding

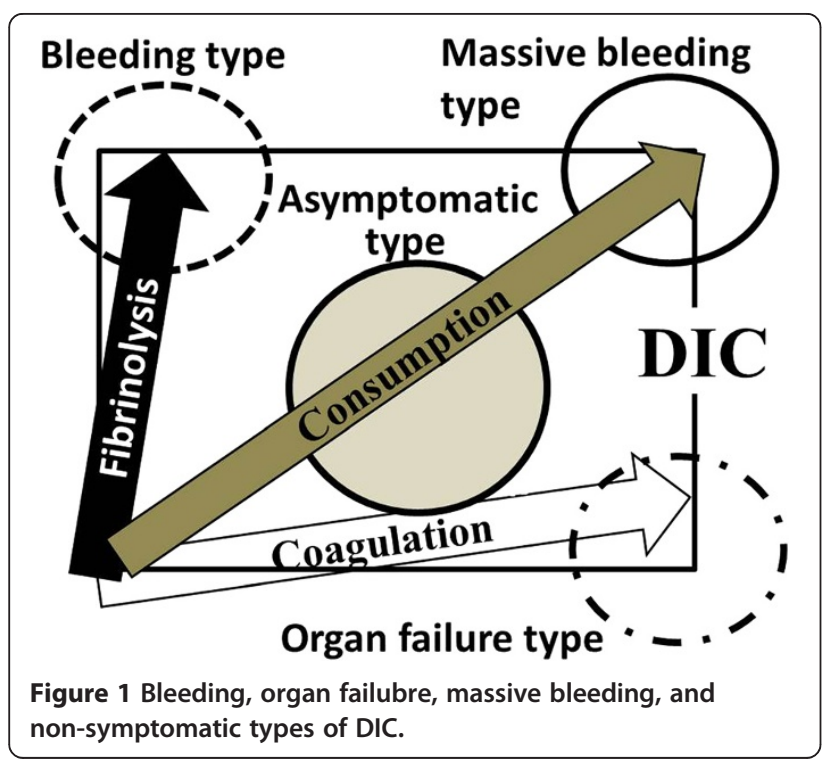

is the primary symptom; this type is called the bleeding type or hyperfibrinolysis predominance type of DIC. This form of DIC is often seen in patients with leukemia, such as acute promyelocytic leukemia (APL), obstetric diseases, or aortic aneurysms [2,7]. On the other hand, when the vector for hypercoagulation is remarkable and dominant, organ failure is the main symptom; this type of DIC is called the organ failure type, hypercoagulation predominance type or hypofibrinolysis type of DIC. This form of DIC is often observed in patients with infection, particularly sepsis. An increase in the level of plasminogen activator inhibitor I (PAI-I) induced by markedly increased levels of cytokines $[8,9]$ and lipopolysaccharide (LPS) [2,7] in the blood has been reported to a cause of hypofibrinolysis. Moreover, neutrophil extracellular traps (NETs) [10], which release DNA with histone, neutrophil elastase, and cathepsin G in order to trap and kill pathogens, are present in patients with sepsis. Histones promote the apoptosis of vascular endothelial cells and platelet aggregation [11], while neutrophil elastase and cathepsin G decompose tissue factor pathway inhibitor (TFPI) in order to promote thrombus formation [12]. Moreover, high mobility group box 1 (HMGB-1) [13] is emitted from injured and dead cells in order to enhance the inflammatory reaction.

When both vectors for hypercoagulation and hyperfibrinolysis are remarkable and strong, major bleeding occurs, followed by death, if a sufficient amount of blood 
is not transfused; this type of DIC is called the massive bleeding or consumptive type of DIC. This form of DIC is observed in patients who exhibit major bleeding after major surgery or in those with obstetric diseases.

When both vectors are weak, there are almost no clinical symptoms, although abnormalities in clinical laboratory tests are observed; this type of DIC is called the nonsymptomatic type of DIC or pre-DIC [14,15]. In a retrospective study [15], the treatment of pre-DIC was reported to be effective. The diagnosis and treatment of the four types of DIC differ [3]. Furthermore, the diagnosis and treatment of DIC is complicated by the fact that the types of DIC may shift or change. Patients with DIC caused by sepsis (organ failure type), hematological malignancy, or obstetrics (bleeding type) can be successfully treated for DIC, whereas DIC associated with solid cancers may not respond to standard treatments [16]. As DIC associated with solid cancers differs from the above four types of DIC, it should be analyzed separately.

\section{Diagnosis of DIC Scoring system}

Various underlying clinical conditions can have an effect on the laboratory parameters that are usually obtained to diagnose DIC, such as global coagulation tests, the platelet count, prothrombin time (PT), and the fibrinogen, fibrinogen, and fibrin degradation products (FDPs). In order to facilitate the diagnostic process for detecting DIC, the use of a scoring system is recommended by each of the four different guidelines [3-6]. Three different diagnostic criteria incorporating similar global coagulation tests have been established by the ISTH/ SSC [1], Japanese Ministry Health, Labour and Welfare (JMHLW) [17], and Japanese Association of Acute Medicine (JAAM) [18]. The JMHLW score is well correlated with the severity of DIC and can be used to predict the outcome of the disease [14]. The ISTH overt DIC score is useful and specific for diagnosing DIC due to infective and non-infective etiologies $[13,19]$. The JAAM score is sensitive for detecting septic DIC and is correlated with the ISTH and JMHLW scores and disease outcome $[13,18]$. A prospective study in Japan reported no significant differences in the odds ratio for predicting DIC outcomes among these three diagnostic criteria [20], suggesting that the identification of molecular hemostatic markers and changes of global coagulation tests is required in addition to the application of scoring systems. The use of a combination of tests repeated over time in patients with suspected DIC can be used to diagnose the disorder with reasonable certainty in most cases [21-23]. A template for a non-overt-DIC scoring system, including global coagulation tests, changes in global coagulation tests as well as hemostatic molecular markers, has been proposed $[1,24,25]$.
The bleeding type of DIC can be easily diagnosed using the ISTH overt-DIC [1] and JMHLW [17] criteria, while the organ failure type of DIC is diagnosed according to the JAAM diagnostic criteria [18]. The massive bleeding (consumptive) type of DIC can be diagnosed using any of the three diagnostic criteria $[1,17,18]$; however, it is difficult to diagnose the non-symptomatic type of DIC using these criteria. The use of hemostatic molecular markers is required to diagnose the non-symptomatic type of DIC.

\section{Laboratory tests}

Global coagulation tests provide important evidence regarding the degree of coagulation factor activation and consumption. Although the PT is prolonged in approximately $50 \%$ of patients with DIC at some point during their clinical course [21], abnormalities are often observed in patients with liver disease or vitamin $\mathrm{K}$ deficiency. A reduction in the platelet count or clear downward trend in subsequent measurements is a sensitive sign of DIC [3], although this pattern is also observed in patients with bone marrow disorders. A reduced fibrinogen level is a valuable indicator regarding a diagnosis of DIC due to leukemia or obstetric diseases; however, it is not observed in most septic DIC patients [3]. Elevated fibrin-related markers (FRMs), such as FDP [26], D-dimer [27], or soluble fibrin (SF), reflect fibrin formation. SF [28] assays offer theoretical advantages in detecting DIC, more closely reflecting the effects of thrombin on fibrinogen, although the half-life is short. It is important to consider that many conditions, such as trauma, recent surgery, bleeding, or venous thromboembolism (VTE), are associated with elevated FRMs. Reductions in the levels of natural anticoagulants, such as antithrombin (AT) and protein $\mathrm{C}$, are common in patients with DIC. Although measuring the AT activity is useful for achieving the full efficacy of heparin [29], this parameter cannot be quickly and easily measured in all hospitals. These activities are correlated with the liver function and/or concentration of albumin. A reduced ADAMTS13 (a disintegrin-like and metalloproteinase with thrombospondin type 1 motifs 13) activity and elevated soluble thrombomodulin (TM), PAI-I, and von Willebrand factor propeptide levels are often observed in patients with DIC and have been shown to have prognostic significance [30-32]. The biphasic waveform of the activated partial thromboplastin time (APTT) has been shown to be associated with DIC and appears to have a positive predictive value for the disease [33,34]. Although many attractive markers for DIC have been reported, no single marker can be used to diagnose DIC alone (Table 2). Therefore, the above four guidelines [3-6] recommend that DIC could not be diagnosed according to the level of a single marker but rather based on the combination of laboratory markers. Among the 
Table 2 Laboratory tests for DIC

\begin{tabular}{llll}
\hline & Abnormality in DIC & Other cause for the abnormality & Adequate type of DIC \\
\hline PT & Prolongation & Liver dysfunction, vitamin K deficiency & OF, BL, MB \\
FDP, D-dimer & Elevation & Venous thromboembolism, operation & $B L, N S, O F$ \\
Fibrinogen & Reduction & Liver dysfunction & $B L, M B$ \\
Platelet count & Reduction & Bone marrow disorders & OF, MB, BL, NS \\
AT/PC & Reduction & Liver dysfunction, capillary leak syndrome & OF \\
SF/TAT & Elevation & Venous thromboembolism, operation & OF, NS, BL, MS \\
TM & Elevation & Renal dysfunction, organ failure & OF \\
WWFpp, PAI-I & Elevation & Organ failure & OF \\
ADATMTS13 & Reduction & Liver dysfunction, thrombotic microangiopathy & OF \\
APTT & Biphasic waveform & Infection & OF \\
PPIC & Elevation & Venous thromboembolism, operation & $B L, M B$
\end{tabular}

PT, prothrombin time; FDP, fibrinogen and fibrin degradation products; SF, soluble fibrin; AT, antithrombin; PC, protein C; TAT, thrombin AT complex; VWFpp, von Willebrand factor propeptide; PAI-I, plasminogen activator inhibitor-l; APTT, activated partial thromboplastin time; PPIC, plasmin-plasmin inhibitor complex; OF, organ failure type of DIC; BL, bleeding type of DIC; MB, massive bleeding type of DIC; NS, non-symptomatic type of DIC.

four types of DIC, PT, fibrinogen, and platelets are important parameters for diagnosing the massive bleeding type of DIC, while fibrinogen, FDP, and plasmin-plasmin inhibitor complex (PPIC) are important for detecting the bleeding type of DIC. Meanwhile, platelets, PT, and AT are important for diagnosing the organ failure type of DICand hemostatic molecular markers, such as SF and the thrombin-AT complex, are important for diagnosing the non-symptomatic type of DIC.

\section{Treatment of DIC}

\section{Treatment of the underlying disease}

The cornerstone of DIC treatment is providing treatment for the underlying disorders, such as the administration of antibiotics or surgical drainage in patients with infectious diseases and anticancer drugs or surgery in patients with malignant diseases. All four guidelines [3-6] agree on this point, although there is no highquality evidence for the efficacy of treating the underlying disorder in DIC patients. DIC spontaneously resolves in many cases when the underlying disorder is properly managed and improved. However, some cases require additional supportive treatment specifically aimed at abnormalities in the coagulation system. A randomized controlled trial (RCT) of the use of all-trans retinoic acid (ATRA) compared with conventional chemotherapy in patients with APL showed that the mortality rate was significantly lower in the ATRA group [35]. ATRA exerts differential effects on APL progression, as well as anticoagulant and antifibrinolytic effects [36]. Similarly, several RCTs of the treatment of sepsis [37-42] and DIC [43] have shown parallel improvements in coagulation derangement and DIC, although the data have not always been concordant. Treating the underlying disorder is first required in patients with bleeding, organ failure, and nonsymptomatic types of DIC, while blood transfusions are needed in patients with the massive bleeding type of DIC (Table 3).

\section{Blood transfusion}

Markedly low levels of platelets and coagulation factors, particularly fibrinogen, may increase the risk of bleeding. The above four guidelines [3-6] recommended the administration of platelet concentrate (PC) and fresh frozen plasma (FFP) in DIC patients with active bleeding or those at high risk of bleeding requiring invasive procedures, without high-quality evidence. The threshold for transfusing platelets depends on the clinical state of the DIC patient. In general, PC is administered in DIC patients with active bleeding and a platelet count of $\leqq 50 \times$ $10^{9} / 1$. A much lower threshold of 10 to $20 \times 10^{9} / 1$ is adopted in non-bleeding patients who develop DIC after undergoing chemotherapy. PC may be administered at higher levels in patients perceived to be at high risk of bleeding based on other clinical or laboratory features [44]. The transfusion of PC or FFP is usually performed in patients with the massive bleeding or bleeding types

\section{Table 3 Treatment of DIC in four types of DIC}

\begin{tabular}{lllll}
\hline Treatment & $\begin{array}{l}\text { Non- } \\
\text { symptomatic } \\
\text { type }\end{array}$ & $\begin{array}{l}\text { Organ } \\
\text { failure } \\
\text { type }\end{array}$ & $\begin{array}{l}\text { Bleeding } \\
\text { type }\end{array}$ & $\begin{array}{l}\text { Massive } \\
\text { bleeding } \\
\text { type }\end{array}$ \\
\hline $\begin{array}{l}\text { Underlying conditions } \\
\text { Blood transfusion }\end{array}$ & $\mathrm{R}$ & $\mathrm{R}$ & $\mathrm{R}$ & \\
Heparin & $\mathrm{R}$ & $\mathrm{R}$ & $\mathrm{R}$ \\
Anti-Xa & & $\mathrm{NR}$ & $\mathrm{NR}$ \\
$\begin{array}{l}\text { Synthetic protease } \\
\text { inhibitor }\end{array}$ & & $\mathrm{NR}$ & $\mathrm{NR}$ \\
Natural protease inhibitor & $\mathrm{NR}$ & $\mathrm{R}$ & $\mathrm{R}$ \\
Antifibrinolytic treatment & $\mathrm{NR}$ & $\mathrm{R}$ & & $\mathrm{NR}$ \\
\hline
\end{tabular}

$\mathrm{R}$, recommended; NR, not recommended. 
of DIC. It is necessary to use large volumes of plasma in order to correct coagulation defects associated with a prolonged APTT or PT (greater than 1.5 times the normal value) or decreased fibrinogen level (less than $1.5 \mathrm{~g} / \mathrm{dl}$ ). An initial dose of $15 \mathrm{ml} / \mathrm{kg}$ of FFP is clinically recommended and usually administered. As the consequences of volume overload must be considered in this context, smaller volumes of prothrombin complex concentrate may be useful in this setting. As specific deficiencies in fibrinogen associated with the massive bleeding type of DIC can be corrected with the administration of purified fibrinogen concentrates or cryoprecipitate, three of the guidelines recommended these treatments (Table 3). The response to blood component therapy should be monitored both clinically and with repeated assessments of the platelet count and coagulation parameters following the administration of these components. The efficacy and safety of recombinant factor VIIa in DIC patients with life-threatening bleeding are unknown, and this treatment should be used with caution or as part of a clinical trial.

\section{Heparin}

Although the administration of anticoagulant treatment is a rational approach based on the notion that DIC is characterized by extensive activation of coagulation, there are several differences in the recommendations for the use of heparin in DIC patients between the four guidelines (Table 1) [3-6]. Therapeutic doses of heparin should be considered in cases of DIC in which thrombosis predominates. A small RCT showed that low molecular weight heparin $(\mathrm{LMWH})$ is superior to unfractionated heparin (UFH) for treating DIC [45], suggesting that the use of LMWH is preferred to that of UFH in these cases. The level of inhibition achieved with $\mathrm{LMWH}$ is higher for activated coagulation factor $\mathrm{Xa}(\mathrm{Xa})$ than for thrombin. $\mathrm{Pa}$ tients with DIC are at high risk of VTE events, and the administration of VTE prophylaxis using UFH, LMWH, and/or mechanical methods has become the standard of care in patients with DIC $[46,47]$. Although experimental studies have shown that heparin can at least partly inhibit the activation of coagulation in the setting of DIC [48], there are no RCTs demonstrating that the use of heparin in patients with DIC results in improvements in clinically relevant outcomes. A recent large trial of patients with severe sepsis showed a non-significant benefit of low-dose heparin on the 28-day mortality and underscored the importance of not discontinuing heparin treatment in patients with DIC and abnormal coagulation parameters [29]. Meanwhile, the 28-day mortality is lower in placebo groups treated with heparin than in placebo groups without heparin according to subclass analyses [49] of RCT of severe sepsis $[37,38,42]$. Although it is not easy to quickly measure the AT level in all hospitals in order to decide whether to administer urgent heparin treatment, measuring this parameter is useful for achieving the full efficacy of heparin. The administration of heparin is not recommended in patients with bleeding or massive bleeding type of DIC due to the increased risk of bleeding, although it is recommended in those with the nonsymptomatic type of DIC in order to prevent the onset of deep vein thrombosis (DVT) (Table 3).

\section{Anti-Xa agents}

Both Fondaparinux ${ }^{\bullet}$ and Danaparoid sodium ${ }^{\circ}$ activate AT specifically to inhibit Xa. Treatment with Fondaparinux ${ }^{\circ}$ is recommended for the prophylaxis of DVT after orthopedic surgery; however, there is little evidence to support its use in critically ill patients and those with other type of DIC. Danaparoid sodium ${ }^{\circ}$ is used to treat DIC in Japan, although no RCTs have shown any reductions in mortality or the rate of resolution of DIC. There is significant evidence for the use of these drugs as prophylaxis for DVT [50,51]; however, there is little evidence for the use of these agents in patients with DIC, and they are not recommended in those with the bleeding or massive bleeding type of DIC (Table 3). These drugs are also not recommended in patients with renal failure.

\section{Synthetic protease inhibitors}

Synthetic protease inhibitors, such as Gabexate mesilate ${ }^{\circ}$ and nafamostat ${ }^{\circ}$, exhibit multiple-functions, including antagonistic effects on the kinin/kallikrein system, fibrinolysis, complement system, and coagulation system. Gabexate mesilate ${ }^{\circ}$ and nafamostat ${ }^{\circ}$ have been frequently used and evaluated in Japan [13,52,53]; however, there are no RCTs showing any reductions in mortality or improvements in the rate of resolution of DIC. As these drugs have mild anticoagulant and antifibrinolytic effects, they are often used in patients with the bleeding, massive bleeding, and non-symptomatic types of DIC (Table 3).

\section{Natural protease inhibitor}

The use of agents capable of restoring dysfunctional anticoagulant pathways in patients with DIC has been studied extensively. Although there are many RCTs of clinically ill patients, almost all RCTs have been carried out in patients with sepsis, with few RCTs of patients with DIC, suggesting that BCSH and SISET determined their recommendations for DIC treatment based on studies of sepsis, not DIC.

$\mathrm{AT}$ and the heparin/heparinoid complex primarily inhibits $\mathrm{Xa}$ and thrombin, while the APC/TM system inhibits thrombin, FVa, and FVIIIa (Figure 2). Each of the four guidelines [3-6] provides different recommendations regarding the use of anticoagulant factor concentrates (Table 1). A large-scale multicenter RCT directly assessing the effects of AT concentrate on mortality in 


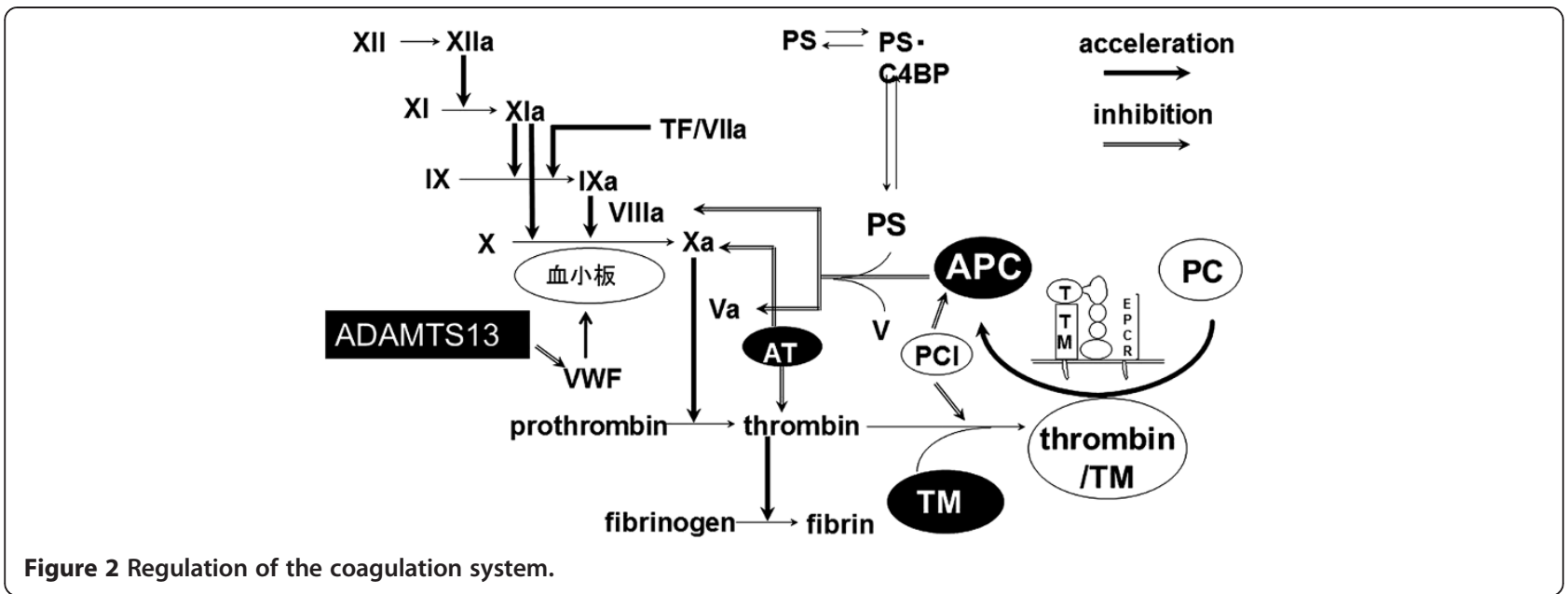

patients with severe sepsis showed no significant reductions in those treated with AT concentrate [37]. Interestingly, the subgroup of patients with DIC and who did not receive heparin showed a remarkable survival benefit [54]; however, this finding requires prospective validation. In one prospective multicenter survey, the efficacy of AT was higher in the 3,000 units/day group than in the 1,500 units/day group [55].

The clinical efficacy of recombinant human activated protein $\mathrm{C}$ (rhAPC) in patients with severe sepsis was demonstrated in a large RCT [38], although a prospective trial of septic patients with relatively low disease severity did not show any benefits of rhAPC therapy [39]. The withdrawal of rhAPC from sepsis treatment regimens was proposed after an RCT of septic shock failed to show any benefits [40]. Meanwhile, treatment with plasma-derived APC improved outcomes in a small RCT [56] in Japan; however, the drug is not approved for the treatment of DIC. There are no useful RCTs of the administration of protein C concentrate to treat sepsis or DIC.

One RCT comparing treatment with rhTM with that of UFH [43] showed that rhTM therapy significantly increased the rate of resolution of DIC, although mortality was not significantly decreased. In another study of DIC, treatment with rhTM relatively reduced mortality and significantly reduced the severity of organ failure compared to a placebo [57]. Another RCT of severe sepsis showed that the administration of rhTM tended to improve mortality [41].

The administration of AT, rhTM, or APC may be considered in DIC patients. Further prospective evidence from RCTs confirming a benefit is required [6]. Treatment with AT and rhTM is recommended in patients with the organ failure type of DIC (Table 3).

\section{Antifibrinolytic treatment}

Antifibrinolytic agents are effective in treating bleeding, although the use of these drugs in patients with the organ failure or non-symptomatic type of DIC is generally not recommended [58]. An exception may be made in those with the bleeding or major bleeding type of DIC. The four guidelines [3-6] exhibit some differences in these recommendations (Table 1). One study of APL demonstrated a beneficial effect of antifibrinolytic agents in this situation [59]; however, cases complicated with severe thrombosis due to the combined use of ATRA and tranexamic acid have been documented [60]. A recent RCT [61] showed that treatment with tranexamic acid significantly reduces the mortality of patients with trauma. The administration of antifibrinolytic agents in these cases must occur in the early period of management before the levels of PAI- 1 and other endogenous antifibrinolytics become elevated.

\section{Conclusions}

In conclusion, DIC is categorized into bleeding, organ failure, massive bleeding, and non-symptomatic types. The diagnosis and treatment of DIC should be carried out in accordance with the type of DIC based on the four guidelines on DIC.

\section{Abbreviations}

ADAMTS13: a disintegrin-like and metalloproteinase with thrombospondin type 1 motifs 13; APL: acute promyelocytic leukemia; APTT: activated partial thromboplastin time; AT: antithrombin; ATRA: all-trans retinoic acid;

BCSH: British Committee for Standards in Haematology; DIC: disseminated intravascular coagulation; FDP: fibrinogen and fibrin degradation products; FFP: fresh frozen plasma; FRMs: fibrin-related markers; HMGB-1: high mobility group box 1; ISTH: International Society of Thrombosis and Haemostasis; JAAM: Japanese Association of Acute Medicine; JMHLW: Japanese Ministry Health, Labour and Welfare; JSTH: Japanese Society of Thrombosis and Hemostasis; LMWH: low molecular weight heparin; LPS: lipopolysaccharide; NETs: neutrophil extracellular traps; PAI-I: plasminogen activator inhibitor I; PC: platelet concentrate; PT: prothrombin time; RCT: randomized controlled trial; rh: recombinant human activated protein C; SF: soluble fibrin; SISET: Italian Society for Thrombosis and Haemostasis; SSC: Scientific and Standardization Committee; TFPI: tissue factor pathway inhibitor; TM: thrombomodulin; UFH: unfractionated heparin; VTE: venous thromboembolism. 


\section{Competing interests}

None of the authors disclose any financial or personal relationships with other people or organizations that could inappropriately influence (bias) their work. Examples of potential conflicts of interest include employment, consultancies, stock ownership, honoraria, paid expert testimony, patent applications/registrations, and grants or other funding.

\section{Authors' contributions}

HW mainly contributed to write this paper. TM and YY mainly contributed to review references. All of authors discussed for this review. All authors read and approved the final manuscript.

\section{Acknowledgements}

This study was supported in part by research grants from the Japanese Ministry of Health, Labour and Welfare and the Japanese Ministry of Education, Science, Sports and Culture.

\section{Author details}

'Department of Molecular and Laboratory Medicine, Mie University School of Medicine, 2-174 Edobashi, Tsu, Mie 514-8507, Japan. ${ }^{2}$ Department of Blood Transfusion, Mie University School of Medicine, 2-174 Edobashi, Tsu, Mie 514-8507, Japan. ${ }^{3}$ Department of Hematology and Oncology, Mie University School of Medicine, 2-174 Edobashi, Tsu, Mie 514-8507, Japan.

\section{Received: 18 December 2013 Accepted: 10 February 2014} Published: 20 February 2014

\section{References}

1. Taylor FB, Toh CH, Hoots WK, Wada H, Levi M: Towards definition, clinical and laboratory criteria, and a scoring system for disseminated intravascular coagulation. Thromb Haemost 2001, 86:1327-1330.

2. Wada H: Disseminated intravascular coagulation. Clin Chim Acta 2004, 344:13-21.

3. Levi M, Toh $\mathrm{CH}$, Thachil J, Watson HG: Guidelines for the diagnosis and management of disseminated intravascular coagulation. British Committee for Standards in Haematology. Br J Haematol 2009, 145:24-33.

4. Wada H, Asakura H, Okamoto K, Iba T, Uchiyama T, Kawasugi K, Koga S, Mayumi T, Koike K, Gando S, Kushimoto S, Seki Y, Madoiwa S, Maruyama I, Yoshioka A, Japanese Society of Thrombosis Hemostasis/DIC subcommittee: Expert consensus for the treatment of disseminated intravascular coagulation in Japan. Thromb Res 2010, 125:6-11.

5. Di Nisio M, Baudo F, Cosmi B, D'Angelo A, De Gasperi A, Malato A, Schiavoni M, Squizzato A, Italian Society for Thrombosis and Haemostasis: Diagnosis and treatment of disseminated intravascular coagulation: guidelines of the Italian society for haemostasis and thrombosis (SISET). Thromb Res 2012, 129:e177-e184

6. Wada H, Thachil J, Di Nisio M, Mathew P, Kurosawa S, Gando S, Kim HK, Nielsen JD, Dempfle CE, Levi M, Toh CH, The Scientific Standardization Committee on DIC of the International Society on Thrombosis Haemostasis: Guidance for diagnosis and treatment of DIC from harmonization of the recommendations from three guidelines. J Thromb Haemost 2013, 11:761-767.

7. Wada H, Matsumoto T, Hatada T: Diagnostic criteria and laboratory tests for disseminated intravascular coagulation. Expert Rev Hematol 2012, 5:643-652.

8. Wada H, Tamaki S, Tanigawa M, Takagi M, Deguchi A, Mori Y, Katayama N, Yamamoto T, Deguchi K, Shirakawa S: Plasma level of IL-1 $\beta$ in disseminated intravascular coagulation. Thromb Haemost 1991, 65:364-368.

9. Wada H, Ohiwa M, Kaneko T, Tamaki S, Tanigawa M, Takagi M, Mori M, Shirakawa M: Plasma level of tumor necrosis factor in disseminated intravascular coagulation. Am J Hematol 1991, 37:147-151.

10. Brinkmann V, Reichard U, Goosmann C, Fauler B, Uhlemann Y, Weiss DS, Weinrauch Y, Zychlinsky A: Neutrophil extracellular traps kill bacteria. Science 2004, 303:1532-1535.

11. Fuchs TA, Brill A, Duerschmied D, Schatzberg D, Monestier M, Myers DD Jr, Wrobleski SK, Wakefield TW, Hartwig JH, Wagner DD: Extracellular DNA traps promote thrombosis. Proc Natl Acad Sci U S A 2010, 107:15880-15885.

12. Massberg S, Grahl L, von Bruehl ML, Manukyan D, Pfeiler S, Goosmann C, Brinkmann V, Lorenz M, Bidzhekov K, Khandagale AB, Konrad I, Kennerknecht E, Reges K, Holdenrieder S, Braun S, Reinhardt C, Spannagl M, Preissner KT, Engelmann B: Reciprocal coupling of coagulation and innate immunity via neutrophil serine proteases. Nat Med 2010, 16:887-896.
13. Hatada T, Wada H, Nobori T, Okabayashi K, Maruyama K, Abe Y, Uemoto S, Yamada S, Maruyama I: Plasma concentrations and importance of high mobility group box protein in the prognosis of organ failure in patients with disseminated intravascular coagulation. Thromb Haemost 2005, 94:975-979.

14. Wada H, Wakita Y, Nakase T, Shimura M, Hiyoyama K, Nagaya S, Mori Y, Shiku $\mathrm{H}$ : Outcome of disseminated intravascular coagulation in relation to the score when treatment was begun. Thromb Haemost 1995, 74:848-852.

15. Wada H, Minamikawa K, Wakita Y, Nakase T, Kaneko T, Ohiwa M, Tamaki S, Deguchi A, Mori Y, Deguchi K, Shirakawa S: Hemostatic study before onset of disseminated intravascular coagulation. Am J Hematol 1993, 43:190-194.

16. Kawasugi K, Wada H, Hatada T, Okamoto K, Uchiyama T, Kushimoto S, Seki Y, Okamura T, Nobori T, Japanese Society of Thrombosis Hemostasis/DIC subcommittee: Prospective evaluation of hemostatic abnormalities in overt DIC due to various underlying diseases. Thromb Res 2011, 128:186-190.

17. Kobayashi N, Maegawa T, Takada M, Tanaka H, Gonmori H: Criteria for diagnosis of DIC based on the analysis of clinical and laboratory findings in 345 DIC patients collected by the research committee on DIC in Japan. Bibl Haemotol 1983, 49:265-275.

18. Gando S, Iba T, Eguchi Y, Ohtomo Y, Okamoto K, Koseki K, Mayumi T, Murata A, Ikeda T, Ishikura H, Ueyama M, Ogura H, Kushimoto S, Saitoh D, Endo S, Shimazaki S, Japanese Association for Acute Medicine Disseminated Intravascular Coagulation (JAAM DIC) Study Group: A multicenter, prospective validation of disseminated intravascular coagulation diagnostic criteria for critically ill patients: comparing current criteria. Crit Care Med 2006, 34:625-631.

19. Gando S, Wada H, Asakura H, Iba T, Eguchi Y, Okamoto K, Ohtomo Y, Kawasugi K, Koga S, Koseki K, Tsuji H, Mayumi T, Murata A, Nakagawa M, Endo S: Evaluation of new Japanese diagnostic criteria for disseminated intravascular coagulation in critically ill patients. Clin Appl Thromb Hemost 2005, 11:71-76.

20. Takemitsu T, Wada H, Hatada T, Ohmori Y, Ishikura K, Takeda T, Sugiyama T, Yamada N, Maruyama K, Katayama N, Isaji S, Shimpo H, Kusunoki M, Nobori $\mathrm{T}$ : Prospective evaluation of three different diagnostic criteria for disseminated intravascular coagulation. Thromb Haemost 2011, 105:40-44.

21. Bick R: Disseminated intravascular coagulation: objective clinical and laboratory diagnosis, treatment, and assessment of therapeutic response. Semin Thromb Hemost 1996, 22:69-88.

22. Levi M, Ten Cate H: Disseminated intravascular coagulation. N Engl J Med 1999, 341:586-592.

23. Toh CH, Dennis M: Disseminated intravascular coagulation, old disease, new hope. BMJ 2003, 327:974-977.

24. Toh $\mathrm{CH}$, Hoots WK: The scoring system of the Scientific and Standardisation Committee on Disseminated Intravascular Coagulation of the International Society on Thrombosis and Haemostasis: a 5-year overview. J Thromb Haemost 2007, 5:604-606.

25. Wada H, Hatada T, Okamoto K, Uchiyama T, Kawasugi K, Mayumi T, Gando S, Kushimoto S, Seki Y, Madoiwa S, Okamura T, Toh CH, Japanese Society of Thrombosis Hemostasis/DIC subcommittee: Modified non-overt DIC diagnostic criteria predict the early phase of overt-DIC. Am J Hematol 2010, 85:691-699.

26. Prisco D, Paniccia R, Bonechi F, Francalanci I, Abbate R, Gensini GF: Evaluation of new methods for the selective measurement of fibrin and fibrinogen degradation products. Thromb Res 1989, 56:547-551.

27. Shorr AF, Trotta RF, Alkins SA, Hanzel GS, Diehl LF: D-dimer assay predicts mortality in critically ill patients without disseminated intravascular coagulation or venous thromboembolic disease. Intens Care Med 1999, 25:207-210.

28. Wada H, Sakuragawa N: Are fibrin-related markers useful for the diagnosis of thrombosis? Semin Thromb Hemost 2008, 34:33-38.

29. Levi M, Levy M, Williams MD, Douglas I, Artigas A, Antonelli M, Wyncoll D, Janes J, Booth FV, Wang D, Sundin DP, Macias WL: Prophylactic heparin in patients with severe sepsis treated with drotrecogin alfa (activated). Am J Respir Crit Care Med 2007, 176:483-490.

30. Wada H, Mori Y, Shimura M, Hiyoyama K, Nakasaki T, loka M, Nakano M, Nishikawa M, Kumeda K, Nakamura S, Shiku H: Poor outcome in disseminated intravascular coagulation or thrombotic thrombocytopenic purpura patients with severe vascular endothelial cell injuries. Am J Hematol 1998, 58:189-194.

31. Faust SN, Levin M, Harrison OB, Goldin RD, Lockhart MS, Kondaveeti S, Laszik Z, Esmon CT, Heyderman RS: Dysfunction of endothelial protein C activation in severe meningococcal sepsis. N Engl J Med 2001, 345:408-416.

32. Habe K, Wada H, Ito-Habe N, Hatada T, Matsumoto T, Ohishi K, Maruyama K, Imai H, Mizutani H, Nobori T: Plasma ADAMTS13, von Willebrand factor 
(VWF) and VWF propeptide profiles in patients with DIC and related diseases. Thromb Res 2012, 129:598-602.

33. Downey C, Kazmi R, Toh CH: Early identification and prognostic implications in disseminated intravascular coagulation through transmittance waveform analysis. Thromb Haemost 1998, 80:65-69.

34. Toh CH, Samis J, Downey C, Walker J, Becker L, Brufatto N, Tejidor L, Jones G, Houdijk W, Giles A, Koschinsky M, Ticknor LO, Paton R, Wenstone R, Nesheim M: Biphasic transmittance waveform in the APTT coagulation assay is due to the formation of a $\mathrm{Ca}(++)$ - dependent complex of $\mathrm{C}$-reactive protein with very-low-density lipoprotein and is a novel marker of impending disseminated intravascular coagulation. Blood 2002, 100:2522-2529.

35. Tallman MS, Andersen JW, Schiffer CA, Appelbaum FR, Feusner JH, Woods WG, Ogden A, Weinstein H, Shepherd L, Willman C, Bloomfield CD, Rowe $J M$, Wiernik PH: All-trans retinoic acid in acute promyelocytic leukemia: long-term outcome and prognostic factor analysis from the North American intergroup protocol. Blood 2002, 100:4298-4302.

36. Tallman MS, Lefèbvre P, Baine RM, Shoji M, Cohen I, Green D, Kwaan HC, Paietta E, Rickles FR: Effects of all-trans retinoic acid or chemotherapy on the molecular regulation of systemic blood coagulation and fibrinolysis in patients with acute promyelocytic leukemia. J Thromb Haemost 2004, 2:1341-1350.

37. Warren BL, Eid A, Singer P, Pillay SS, Carl P, Novak I, Chalupa P, Atherstone A, Penzes I, Kubler A, Knaub S, Keinecke HO, Heinrichs H, Schindel F, Juers M, Bone RC, Opal SM: Caring for the critically ill patient. High-dose antithrombin III in severe sepsis: a randomized controlled trial. JAMA 2001, 286:1869-1878.

38. Bernard GR, Vincent JL, Laterre PF, LaRosa SP, Dhainaut JF, Lopez-Rodriguez A, Steingrub JS, Garber GE, Helterbrand JD, Ely EW, Fisher CJJ: Efficacy and safety of recombinant human activated protein $\mathrm{C}$ for severe sepsis. N Engl J Med 2001, 344:699-709.

39. Abraham E, Laterre PF, Garg R, Levy H, Talwar D, Trzaskoma BL, Francois B, Guy JS, Bruckmann M, Rea-Neto A, Rossaint R, Perrotin D, Sablotzki A, Arkins N, Utterback BG, Macias WL: Drotrecogin alfa (activated) for adults with severe sepsis and a low risk of death. N Engl J Med 2005, 353:1332-1341.

40. Ranieri VM, Thompson BT, Barie PS, Dhainaut JF, Douglas IS, Finfer S, Gårdlund B, Marshall JC, Rhodes A, Artigas A, Payen D, Tenhunen J, Al-Khalidi HR, Thompson V, Janes J, Macias WL, Vangerow B, Williams MD, PROWESS-SHOCK Study Group: Drotrecogin alfa (activated) in adults with septic shock. N Engl J Med 2012, 366:2055-2064.

41. Vincent IL, Ramesh MK, Ernest D, Larosa SP, Pachl J, Aikawa N, Hoste E, Levy H, Hirman J, Levi M, Daga M, Kutsogiannis DJ, Crowther M, Bernard GR, Devriendt J, Puigserver JV, Blanzaco DU, Esmon CT, Parrillo JE, Guzzi L, Henderson SJ, Pothirat C, Mehta P, Fareed J, Talwar D, Tsuruta K, Gorelick KJ, Osawa Y, Kaul I: A randomized, double-blind, placebo-controlled, phase $2 \mathrm{~b}$ study to evaluate the safety and efficacy of recombinant human soluble thrombomodulin, ART-123, in patients with sepsis and suspected disseminated intravascular coagulation. Crit Care Med 2013, 41:2069-2079.

42. Abraham E, Reinhart K, Svoboda P, Seibert A, Olthoff D, Dal Nogare A, Postier R, Hempelmann G, Butler T, Martin E, Zwingelstein C, Percell S, Shu V, Leighton A, Creasey AA: Assessment of the safety of recombinant tissue factor pathway inhibitor in patients with severe sepsis: a multicenter, randomized, placebo-controlled, single-blind, dose escalation study. Crit Care Med 2001, 29:2081-2089.

43. Saito H, Maruyama I, Shimazaki S, Yamamoto Y, Aikawa N, Ohno R, Hirayama A, Matsuda T, Asakura H, Nakashima M, Aoki N: Efficacy and safety of recombinant human soluble thrombomodulin (ART-123) in disseminated intravascular coagulation: results of a phase III, randomized, double-blind clinical trial. J Thromb Haemost 2007, 5:31-41.

44. Levi M, Opal SM: Coagulation abnormalities in critically ill patients. Crit Care 2006, 10:222.

45. Sakuragawa N, Hasegawa H, Maki M, Nakagawa M, Nakashima M: Clinical evaluation of low-molecular-weight heparin (FR-860) on disseminated intravascular coagulation (DIC); a multicenter co-operative double-blind trial in comparison with heparin. Thromb Res 1993, 72:475-500.

46. Samama MM, Cohen AT, Darmon JY, Desjardins L, Eldor A, Janbon C, Leizorovicz A, Nguyen H, Olsson CG, Turpie AG, Weisslinger N: A comparison of enoxaparin with placebo for the prevention of venous thromboembolism in acutely ill medical patients; prophylaxis in medical patients with enoxaparin study group. N Engl J Med 1999, 341:793-800.

47. Patel R, Cook DJ, Meade MO, Griffith LE, Mehta G, Rocker GM, Marshall JC, Hodder R, Martin CM, Heyland DK, Peters S, Muscedere J, Soth M, Campbell N, Guyatt GH: Burden of illness in venous thromboembolism in critical care: a multicenter observational study. J Crit Care 2005, 20:341-347.
48. Pernerstorfer $T$, Hollenstein $U$, Hansen J, Knechtelsdorfer M, Stohlawetz $P$, Graninger W, Eichler HG, Speiser W, Jilma B: Heparin blunts endotoxininduced coagulation activation. Circulation 1999, 100:2485-2490.

49. Polderman $\mathrm{KH}$, Girbes AR: Drug intervention trials in sepsis: divergent results. Lancet 2004, 363:1721-1723.

50. Beyer-Westendorf J, Lützner J, Donath L, Radke OC, Kuhlisch E, Hartmann A, Weiss N, Werth S: Efficacy and safety of rivaroxaban or fondaparinux thromboprophylaxis in major orthopedic surgery: findings from the ORTHO-TEP registry. J Thromb Haemost 2012, 10:2045-2052.

51. Girard P, Demaria J, Lillo-Le Louët A, Caliandro R, Le Guillou JL, Crespin M, de Sanctis A, Stern JB: Transfusions, major bleeding, and prevention of venous thromboembolism with enoxaparin or fondaparinux in thoracic surgery. Thromb Haemost 2011, 106:1109-1116.

52. Umeki S, Adachi M, Watanabe M, Yaji S, Soejima R: Gabexate as a therapy for disseminated intravascular coagulation. Arch Intern Med 1988, 148:1409-1412.

53. Nishiyama T, Matsukawa T, Hanaoka K: Is protease inhibitor a choice for the treatment of pre- or mild disseminated intravascular coagulation? Crit Care Med 2000, 28:1419-1422.

54. Kienast J, Juers M, Wiedermann CJ, Hoffmann JN, Ostermann H, Strauss R, Keinecke HO, Warren BL, Opal SM: Treatment effects of high-dose antithrombin without concomitant heparin in patients with severe sepsis with or without disseminated intravascular coagulation. J Thromb Haemost 2006, 4:90-97.

55. Iba T, Saito D, Wada H, Asakura H: Efficacy and bleeding risk of antithrombin supplementation in septic disseminated intravascular coagulation: a prospective multicenter survey. Thromb Res 2012, 130:e129-e133.

56. Aoki N, Matsuda T, Saito H, Takatsuki K, Okajima K, Takahashi H, Takamatsu J, Asakura H, Ogawa N: CTC-111-IM Clinical Research Group. A comparative double-blind randomized trial of activated protein $C$ and unfractionated heparin in the treatment of disseminated intravascular coagulation. Int J Hematol 2002, 75:540-547.

57. Yamakawa K, Fujimi S, Mohri T, Matsuda H, Nakamori Y, Hirose T, Tasaki O, Ogura H, Kuwagata Y, Hamasaki T, Shimazu T: Treatment effects of recombinant human soluble thrombomodulin in patients with severe sepsis: a historical control study. Crit Care 2011, 15:R123.

58. Mannucci PM, Levi M: Prevention and treatment of major blood loss. N Engl J Med 2007, 356:2301-2311.

59. de la Serna J, Montesinos P, Vellenga E, Rayon C, Parody R, Leon A, Esteve J, Bergua JM, Milone G, Deben G, Rivas C, Gonzalez M, Tormo M, az-Mediavilla J, Gonzalez JD, Negri S, Amutio E, Brunet S, Lowenberg B, Sanz MA: Causes and prognostic factors of remission induction failure in patients with acute promyelocytic leukemia treated with all-trans retinoic acid and idarubicin. Blood 2008, 111:3395-3402.

60. Brown JE, Olujohungbe A, Chang J, Ryder WD, Morganstern GR, Chopra R, Scarffe JH: All-trans retinoic acid (ATRA) and tranexamic acid: a potentially fatal combination in acute promyelocytic leukaemia. $\mathrm{Br} J$ Haematol 2000, 110:1010-1012.

61. CRASH-2 trial collaborators, Shakur H, Roberts I, Bautista R, Caballero J, Coats T, Dewan Y, El-Sayed H, Gogichaishvili T, Gupta S, Herrera J, Hunt B, Iribhogbe P, Izurieta M, Khamis H, Komolafe E, Marrero MA, Mejía-Mantilla J, Miranda J, Morales C, Olaomi O, Olldashi F, Perel P, Peto R, Ramana PV, Ravi RR, Yutthakasemsunt S: Effects of tranexamic acid on death, vascular occlusive events, and blood transfusion in trauma patients with significant haemorrhage (CRASH-2): a randomised, placebo-controlled trial. Lancet 2010, 376:23-32.

doi:10.1186/2052-0492-2-15

Cite this article as: Wada et al.: Diagnosis and treatment of disseminated intravascular coagulation (DIC) according to four DIC guidelines. Journal of Intensive Care 2014 2:15. 